\title{
Diagnóstico de leptospirosis de muestras de sangre y cultivo por observación en microscopio de campo oscuro
}

\author{
Piedad Agudelo-Flórez, Marcos Restrepo, Natalí Moreno \\ Instituto Colombiano de Medicina Tropical, Universidad CES, Sabaneta, Antioquia
}

La leptospirosis, una de las zoonosis más extendidas en el mundo, es considerada una enfermedad reemergente, producida por especies patógenas del género Leptospira que comprende, aproximadamente, 13 de las 17 especies descritas hasta el momento; éstas son indistinguibles morfológicamente y su clasificación taxonómica se hace por métodos moleculares. La leptospirosis se presenta con múltiples síntomas inespecíficos y para llegar a la definición de caso confirmado, el personal médico debe, además de reconocer las manifestaciones clínicas que coinciden con leptospirosis, confirmar la sospecha diagnóstica de la enfermedad por laboratorio, bien sea por: 1) observación al microscopio de campo oscuro de la bacteria en muestras de sangre $u$ orina, o en tejidos obtenidos post mórtem y, en este caso, se usan coloraciones especiales de plata o inmunofluorescencia; 2) cultivo positivo (sangre, orina, líquido cefalorraquídeo o muestras post mórtem); 3) incremento o alza cuádruple de los títulos por microaglutinación en sueros pareados tomados con un intervalo de 15 días; 4) título alto único (>1:400) utilizando diagnóstico serológico por microaglutinación o pruebas que detecten IgM, o 5) resultado positivo de la prueba de reacción en cadena de la polimerasa en sangre, orina, líquido cefalorraquídeo o muestras de tejidos post mórtem.

Debido a que las dos primeras formas de diagnóstico requieren de un personal experto para la visualización de Leptospira spp., nos proponemos presentar a la comunidad médica imágenes de referencia de Leptospira spp. que se observan en el microscopio de campo oscuro provenientes de muestras de sangre o de cultivo.

Se necesita disponer de métodos de diagnóstico para leptospirosis en los laboratorios de salud pública, además de personal capacitado para realizarlos, lo cual permite confirmar el diagnóstico clínico de una etiología que como ésta, presenta síntomas comunes a otras enfermedades endémicas en Colombia, como son el dengue y el paludismo.

Palabras clave: leptospirosis/diagnóstico, Leptospira, microscopía.

\section{Diagnosis of leptospirosis by dark-field microscopy of blood samples and culture}

Leptospirosis, one of the most extended zoonosis in the world is considered a reemergent disease. It is produced by the pathogenic species of the genus Leptospira. There are approximately 13 of 17 species described up to date. These species are indistinguishable morphologically and their taxonomic classification is done by molecular methods.

Leptospirosis presents with multiple unspecific clinical symptoms that make it difficult to confirm the case. To verify the diagnoses, the medical personnel need to know how to recognize the clinical manifestations for leptospirosis and to corroborate a good diagnostic suspicion, in addition to ordering the appropriate tests to the laboratory for: 1) dark field microscopy visualization of the bacteria in blood samples, urine or postmortem tissues which need to use special stains like silver stain or immunofluorescence; 2) having positive culture for leptospirosis from blood, urine, CSF or of tissues postmortem; 3) having an increase (fourfold rise) of the tires in microagglutination test from two serum samples taken with an interval of 15 days apart, 4) an elevated unique title (>1:400) using microagglutination for serological diagnosis or IgM detection test, and 5) positive PCR assay in blood, urine, CSF or tissues postmortem.

Due to the fact that the first two tests for diagnosis needs a trained personnel for Leptospira's visualization, we would like to present to the medical community reference images of Leptospira 
species that can be observed by dark field microscopy from as blood as cultures. It is necessary to have methods for leptospirosis in the public health laboratories; additionally, to have qualified personnel to realize them. This will allow confirming a clinical diagnosis with symptoms that resemble other endemic diseases in Colombia, like dengue and malaria.

Key words: leptospirosis/diagnosis, Leptospira, microscopy.

\section{Conflicto de intereses}

Los autores manifiestan que no tienen ningún conflicto de intereses
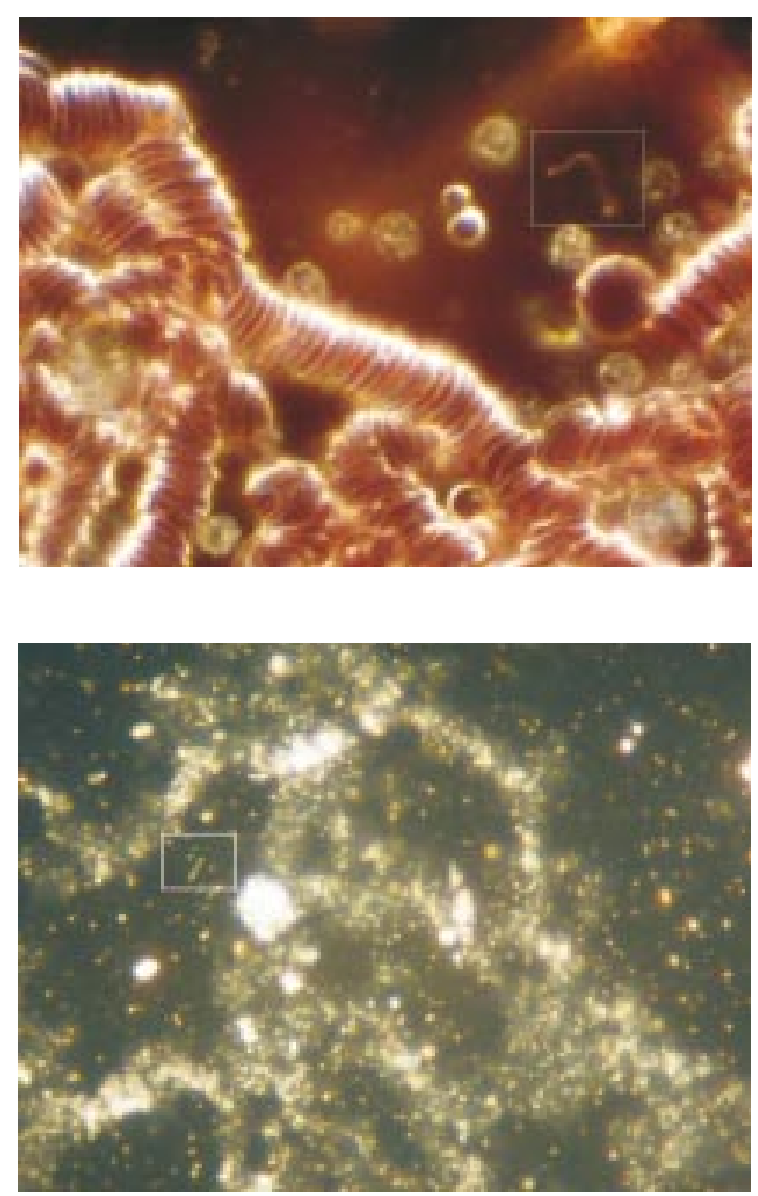

Correspondencia:

Piedad Agudelo-Flórez, Instituto Colombiano de Medicina Tropical, Universidad CES, Carrera 43A No. 52 Sur-99, apartado aéreo 52162,Sabaneta, Antioquia, Colombia. Teléfono: (574) 305 3500, extensión 314; fax: (574) 301 4258

pagudelo@ces.edu.co

Recibido: 27/09/07; aceptado: 18/10/07

\section{Financiación}

Este trabajo fue financiado por el Instituto Colombiano de Medicina Tropical, Universidad CES.

Figura 1. Leptospira sp. en el examen directo de una muestra de sangre obtenida por punción venosa en tubo con anticoagulante, para observación entre portaobjetos y cubreobjetos con microscopio de campo oscuro, 40X. En la fase aguda de la enfermedad, durante la respuesta febril, las leptospiras circulan en la sangre y se pueden observar al microscopio. Nótese la presencia de una forma bacteriana sugestiva de Leptospira sp., con ganchos en ambos extremos y movimiento ondulatorio. La observación directa presenta baja sensibilidad, debido al escaso número de leptospiras presentes en la sangre, con menores posibilidades de observarla, si ya se ha iniciado la terapia con antibióticos. Debe tenerse en cuenta que el observador poco experto puede confundirlas con cadenas proteínicas de la sangre anticoagulada (seudoespiroquetas) y esto puede alterar la especificidad del método. Por este motivo, toda observación directa de una forma sanguínea sugestiva de Leptospira sp. se debe confirmar siempre con un cultivo positivo.

Figura 2. Leptospira sp. al examen directo por microscopio de campo oscuro, de hemocultivo en medio semisólido de Fletcher después de tres semanas de incubación a temperatura de $25^{\circ} \mathrm{C}$ a $28^{\circ} \mathrm{C}, 40 \mathrm{X}$.

Obsérvese la presencia de una forma típica en forma de gancho, sugestiva de Leptospira sp. El cultivo es la prueba de referencia para demostrar la presencia del microorganismo en un fluido corporal que provenga de un paciente con clínica indicativa de leptospirosis, aunque también debe considerarse que ante un resultado negativo de cultivo, no se debe descartar la presencia de enfermedad activa. 

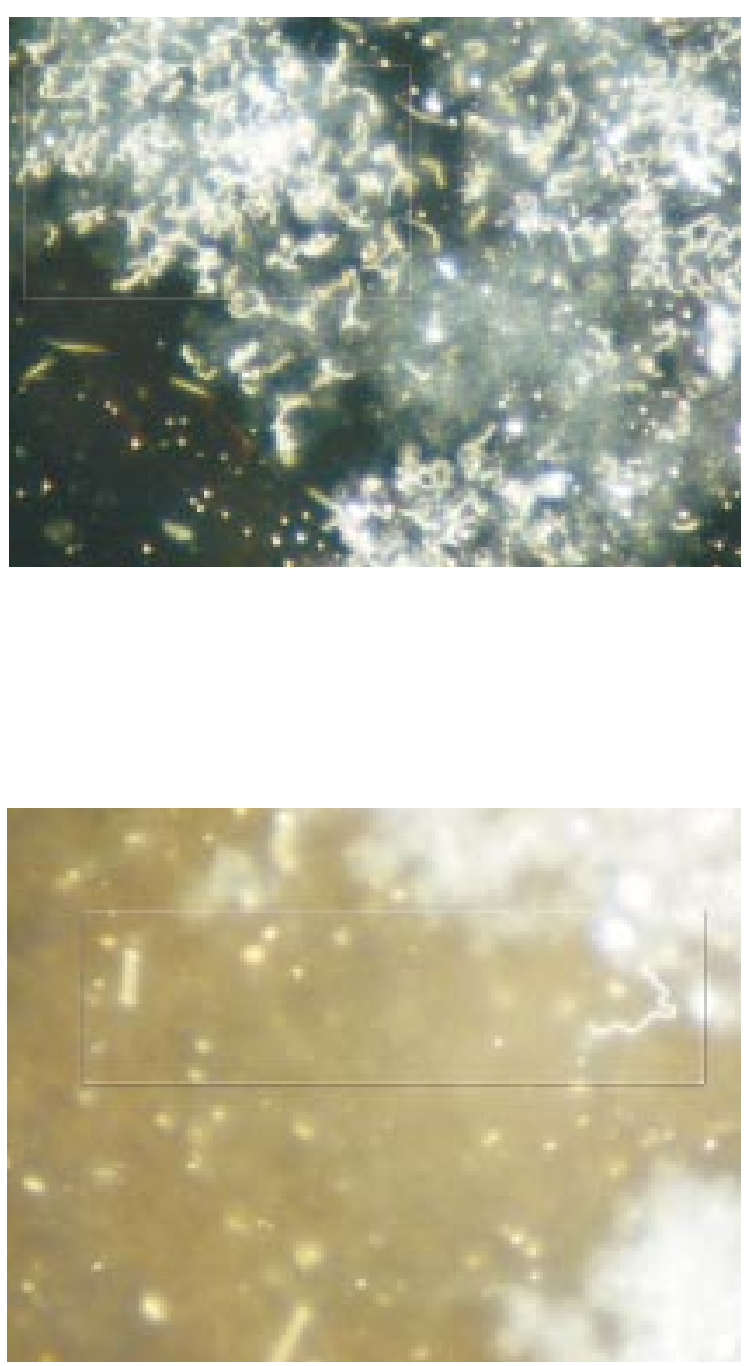

Figura 3. Leptospira sp. al examen directo por microscopio de campo oscuro (de cultivo de sangre en medio líquido Elling-Hausen-McCullough-Johnson-Harris (EMJH), después de cuatro semanas de incubación a temperatura de $25^{\circ} \mathrm{C}$ a $28^{\circ} \mathrm{C}, 40 \mathrm{X}$.

Obsérvese la abundante cantidad de formas sugestivas de Leptospira sp. en este cultivo. Por ser microorganismos de crecimiento lento, se les debe hacer seguimiento a los cultivos con el microscopio de campo oscuro, al menos por un periodo de ocho semanas -la Organización Mundial de la Salud recomienda seguimiento de 12 a 16 semanas-, antes de reportarse como negativos.

Para tener éxito en el cultivo de este microorganismo, se requieren condiciones especiales para su realización, como sembrar la muestra en el menor tiempo posible después de su obtención. En el caso de remitir las muestras para que se cultiven en otro laboratorio debe hacerse a temperatura ambiente pues las bajas temperaturas son deletéreas para las especies patógenas. Es necesario tener en cuenta estas condiciones si se desea tener éxito en el aislamiento de la bacteria.

Figura 4. Leptospira sp. al examen directo con microscopio de campo oscuro de un cultivo de sangre en medio líquido $E M J H$, después de cuatro semanas de incubación a temperatura de $25^{\circ} \mathrm{C}$ a $28^{\circ} \mathrm{C}, 40 \mathrm{X}$.

Obsérvense las diferentes formas sugestivas de Leptospira sp. que pueden encontrarse en los cultivos. Debido a que las especies son indistinguibles morfológicamente, la presencia de un cultivo positivo puede complementarse con la reacción en cadena de la polimerasa para determinar si el aislamiento corresponde a una variedad serológica patógena. 